DOI: $10.17805 /$ zpu.2016.2.25

\title{
Психологические особенности метрической обработки образцов восприятия
}

\author{
И. В. ПОЛЯКОВА \\ (СМОЛЕНСКИЙ ГОСУДАРСТВЕННЫЙ УНИВЕРСИТЕТ)
}

Статья посвящена исследованию проблемы константности восприятия и ее роли в процессе адаптации человека к социокультурному окружению. Цель работы заключалась в установлении психологических детерминант, оказывающих влияние на точность восприятия заданных образцов испытуемыми. В качестве гипотетического выдвинуто предположение о том, что психоэмоциональное состояние испытуемого и локальные межполушарные взаимодействия влияют на точность восприятия и последующее воспроизведение заданного образца.

Описано исследование, в котором приняли участие 19 студентов четвертого курса психолого-педагогического факультета Смоленского государственного университета. Исследование проводилось в марте 2014 г. В ходе эксперимента осуществлялись измерения точности воспроизведения заданного образца с помощью вначале попеременного, а затем одновременного надавливания правой и левой руками испытуемых на клавиши измерительного прибора. Измерения проводились на специально изготовленном для обследования приборе, позволяющем устанавливать величину ошибки воспроизведения автоматически непосредственно в процессе работы. Серии измерений проводились в разных психоэмоциональных состояниях испытуемых: спокойного бодрствования и в состоянии психоэмоционального возбуждения (после интенсивной физической нагрузки).

Компаративное соотнесение полученных результатов подтвердило выдвинутую автором гипотезу о влиянии психоэмоционального состояния испытуемого и локальных межполушарных взаимодействий на точность восприятия и последующего воспроизведения заданного образца, а также уточнило «вклад» межполушарной асимметрии в точность воспроизведения перцептивного образца. В ходе исследования было установлено, что наиболее информативным измерением, позволяющим установить перцептивную зрелость испытуемого, является величина ошибки при восприятии и последующем воспроизведении образца ведущей рукой в состоянии спокойного бодрствования.

Ключевые слова: перцептогенез; метрическая обработка; когнитивные процессы; константность восприятия; точность восприятия; межполушарная асимметрия; психическое напряжение; эмоциональное возбуждение; состояние спокойного бодрствования; гендерные различия

\section{ВВЕАЕНИЕ}

\footnotetext{
Точность восприятия имеет определяющее значение для социальной адаптации, эффективного усвоения культурно-исторического опыта, обучения и воспитания. Понимание психологических механизмов и особенностей, обеспечивающих точность перцепции, важно для диагностики психического развития личности, установления оптимальных сфер профессиональной «пригодности», психологической коррекции и терапии, развития самосознания и саморегуляции.
} 
Многочисленные исследования точности и константности восприятия связаны в основном с изучением зрительной и аудиальной сфер (Гончаров, Емельянова, Тяповкин, 2011; Амитриева, Андерсон, Гельман, 2016; Звягина, Морозова, Теребова, 2011; Bryden, George, Inch, 1990; Ganel, Goodale, 2003). Вместе с тем точность осязания, будучи как бы менее задействованной и поэтому менее исследованной в процессе специально организованного обучения, может выступить в качестве источника сведений о перцептогенезе (становление и развитие перцептивного процесса), относительно свободного от условий социального научения и социального контроля.

Экзистенциальные ситуации в силу их эмоциональной значимости для субъекта влияют на точность его восприятия, которая и предопределяет исход. Целью данной работы является исследование точности восприятия и психоэмоционального состояния субъекта. В качестве гипотетического было выдвинуто предположение о том, что точность восприятия и особенности психоэмоционального состояния взаимосвязаны. В исследовании приняли участие 19 студентов четвертого курса психолого-педагогического факультета Смоленского государственного университета. Исследование проводилось в марте 2014 г.

\section{ОБЗОР ИССАЕАОВАНИЙ}

Идея взаимосвязи нейро-, психофизиологических и перцептивных особенностей личности открывает перспективы уточнения ее ресурсных возможностей, значимых для понимания и прогноза специфики поведения. Специфика поведения связана с особенностями когнитивного развития, социально-психологическое значение которых неоспоримо (Парцалис, 2013: 4), и в значительной мере определяет успешность адаптации к сообществу. Проблема качества адаптации, регулирования поведения и деятельности связана со степенью осознания человеком объективных параметров ситуации, к которой он приспосабливается. Эффективность обеспечения этого процесса связана с точностью восприятия, которая во многом определяет зрелость перцептогенеза.

Роль и значение перцептогенеза в развитии психики широко обсуждается специалистами различных научных отраслей, особенно психоневрологами, неврологами, врачами общей практики, психологами. Исследования психологических механизмов восприятия открывают дополнительные возможности диагностики состояния физического и психического здоровья, поскольку, например, в отличие от личностных опросников, их измерение является относительно свободным от социокультурных стереотипов, принятых с разной степенью осознания, но декларируемых личностью в процессе исследования. Количественные и качественные расхождения параметров объективной ситуации и ее отражение-понимание предопределяют поведение человека, особенно в экстремальных и кризисных ситуациях, поэтому их изучение уточняет понимание механизмов функционирования восприятия, а управление ими повышает личностную эффективность.

Обзор современных исследований перцептогенеза следует начать с декларируемой генетической заданности некоторых видов константности восприятия (Петухов, 2002). Изучение этой проблематики связано прежде всего с исследованием зрительного гнозиса, праксиса и его расстройств. Учеными М. М. Безруких, А. В. Хряниным, Н. Н. Теребовой установлена зависимость зрительного восприятия от гендерных особенностей, которая проявляется уже в младенческом возрасте (Безруких, Хрянин, Теребова, 2013: 22). Общеизвестно, что испытуемые мужского пола традиционно опережают женщин по некоторым показателям. Получены сведения о том, что половые 
различия проявляются в пространственной ориентации: объем зрительно-пространственной памяти мужчин выше, чем у женщин (Coluccia, Louse, 2004: 339). Гендерные различия в зрительном восприятии отраженных и повернутых фигур установлены уже в младенческом возрасте: в возрасте трех-пяти месяцев младенцы мужского пола различают зеркальные изображения двухмерных фигур и изображения по-разному повернутых трехмерных фигур, причем время фиксации их взгляда на знакомых фигурах меньшее, чем на их зеркальных и повернутых изображениях, у девочек таких различий не выявлено (Безруких, Хрянин, Теребова, 2013: 23).

Получены данные о значимых гендерных различиях пространственной организации речевых функций, в частности, в левом полушарии у мужчин и женщин; разная эффективность мнемических процессов в правом и левом полушариях у мужчин (Аля женщин не характерно); у мужчин и женщин вовлечены разные корковые ансамбли на всех этапах обработки речевой информации (Вольф, Разумникова, 2004). Особенности специфического вклада восприятия в функционирование умственных действий человека связывают с широким спектром особенностей, среди них не только гендерные и когнитивные особенности (Ахметова, 2005: 19), но и операционно-технические. Так, Н. В. Звягина, А. В. Морозова и Н. Н. Теребова указывают на различный темп психической активности испытуемых, влияющий на точность зрительного восприятия (Звягина, Морозова, Теребова, 2011: 49). Исследователи А. А. Фарбер и Т. Г. Бетелева связывают темп перцептивной активности с функциональной зрелостью многих корковых структур, объединенных в единую систему (Фарбер, Бетелева, 2005: 29).

Особенности функционирования стратегий зрительного восприятия рассматриваются в различных концепциях, контекстуально связанных с гендерными различиями. Среди них концепция двух принципов обработки пространственной информации (Гончаров, Емельянова, Тяповкин, 2011); интерактивная и независимая стратегии обработки информации (Duemmler et all., 2008); глобальная и локальная стратегии (Bryden et all., 1990). Концепция двух принципов обработки пространственной информации включает топологический и метрический принципы. Топологический принцип обработки (по Ж. Пиаже: воспринимаются общие свойства о расположении предметов в пространстве) распространен на ранних этапах онто- и перцептогенеза, имеет значение для быстрой идентификации отражаемых объектов. Известно, что это как бы инвариантные свойства, они сохраняются при любых деформациях объектов. Топологический принцип обработки понимается как более значимый при коротких предъявлениях, отражении стимулов в периферических полях зрения, особенно в детском возрасте.

Метрическая обработка включает сравнение фигур с имеющимся эталоном восприятия и измерение пространственных характеристик (Bryden et all., 2011). Формирование топологических и метрических представлений имеет гетерохронный характер и осуществляет разный вклад в перцептогенез. Установлено, что в онтогенезе топологические представления формируются раньше остальных и значение топологического принципа обработки пространственной информации постепенно снижается от дошкольного к подростковому возрасту (Schum et all., 2012). О. А. Гончаров, Н. Е. Емельянова, Ю. Н. Тяповкин (Гончаров, Емельянов, Тяповкин, 2011) считают, что топологический принцип обработки зрительной информации является врожденным, реализуется автоматически, вместе с тем с возрастом постепенно усиливается роль метрической обработки. Они установили, что влияние топологического принципа проявляется сильнее на короткой экспозиции стимула, пролонгация времени экс- 
понирования стимула в три-пять раз повышает вероятность включения метрической обработки. Это объясняется тем, что при увеличении времени экспозиции изображения не возникает дефицита информации и приемов для анализа метрических отношений между составляющими объектов, процесс идет дальше в направлении метрических изысканий, реализуя познавательные потребности. Таким образом, развитие метрических представлений как бы ведет за собой перцептогенез.

Аналогичные результаты были получены нами в исследовании ценностей руководителей и собственников предприятий г. Смоленска, принявших участие в российскошведской программе «Развивай свою фирму» (Грушенко, 2012), проведенном нами в 2006 г. Применялась методика Рокича. Анализ ответов 18 испытуемых позволил установить, что соотношение терминальных и инструментальных (операционно-технических) ценностей не является равномерным. Терминальных ценностей оказалось значительно, практически втрое, меньше. В ходе исследования мы обратили внимание на то, что для бизнесменов зрелого возраста (45 лет и более) преимущественное значение имеют операционально-технические ценности. Мы обозначили эту тенденцию условно как «красота игры», подразумевая при этом избирательное отношение к «надлежащим», соответствующим их представлению о должных способах и приемах развития деятельности и поведения (Полякова, 2007: 294). Аругими словами, «удельный вес» топологических, терминальных характеристик объекта или явления в целом снижается в процессе накопления опыта и становится как бы автоматизированным, свернутым. Метрические, операционно-технические, связанные с включением в конкретную деятельность в конкретной ситуации, моменты становятся более актуальными, осознанными и «ресурсозатратными» как в психологическом, так и во временном смыслах. Например, «...в экономическом сознании предпринимателей выявлено возрастание стремления приумножить свой капитал, готовности на свободные денежные средства больше помогать близким, путешествовать и часть направлять на общественные нужды» (Журавлева, 2015: 50).

Метрические представления функционируют по-разному. Исследователи описывают различные стратегии обработки информации о свойствах воспринимаемых объектов, например интерактивную и независимую (Hanisch, Konczak, Dohle, 2001). При интерактивной стратегии в процесс обработки включаются все характеристики объекта в целом и в их соотношениях. При независимой стратегии - только отдельные или значимые, по мнению испытуемого, для конкретной деятельности в конкретной ситуации. Результаты исследований Т. Ганел и М. А. Гудеил (Ganel, Goodale, 2003) также свидетельствуют о том, что взрослые используют различные стратегии обработки информации об объектах при зрительном восприятии, в зависимости от того, какие действия производят с объектом: рассматривают его или действуют с ним. При предметных действиях размеры предметов не соотносятся друг с другом (независимая стратегия), а при рассматривании объектов их размерные характеристики оцениваются и соотносятся (интерактивная стратегия). Установлено, что в отличие от взрослых дети используют интерактивную стратегию в обоих случаях - и при рассматривании, и в случае действия с объектами (Hanisch, Konczak, Dohle, 2001). Интерактивная стратегия реализуется посредством метрических представлений.

Глобальная и локальная стратегии восприятия объекта описаны Брайден, Аж. Георг и Р. Инч (Bryden, George, Inch, 1990): выполнение заданий на мысленное вращение объекта было более әффективным при использовании «глобальной» стратегии восприятия объекта как целостного образа, чем с «локальной», когда анализируются от- 
дельные признаки. Использование этих стратегий у мальчиков и девочек разное. Среди детей 4-12 лет мальчики чаще девочек используют глобальную стратегию (Kramer et all., 1996). Аналогичные результаты были получены в исследованиях А. Цурели и Аж. Эгози (Tzuriel, Egozi, 2010), проведенных среди дошкольников: мальчики показывают лучшие результаты решения заданий на мысленное вращение, чем девочки, поскольку чаще используют глобальную стратегию. Аевочки, наоборот, применяют аналитический (детальный) подход, описывая вербально местоположения отдельных элементов. Установлено, девочки 6-7 лет значительно превосходят мальчиков по уровню сформированности константности зрительного восприятия (Безруких, Хрянин, Теребова, 2013: 33). С одной стороны, девочки раньше и чаще используют метрические представления, с другой стороны, ограничения в скорости предъявления стимульного материала выявили, что женщины эффективнее используют для запоминания образы, это, как установили Н. В. Вольф и О. М. Разумникова (Вольф, Разумникова, 2004), не характерно для мужчин. Иными словами, мужчины берут реванш в развитии метрических представлений на более поздних этапах онтогенеза.

Гендерные различия перцептогенеза изучаются с помощью исследования межполушарной асимметрии. Аокальные межполушарные взаимодействия вносят специфический вклад в решение любой задачи, особенно при выполнении сложных, непривычных заданий, а также заданий, когда реципиенты не испытывают состояния спокойного бодрствования. А. А. Еремина установила, что изменение скорости психической активности связано с изменениями в эмоциональном состоянии человека (Еремина, 2015: 42). Например, опознание зрительного стимула правым и левым полушариями не идентично: левое полушарие осуществляет инвариантное описание объекта, правое целостное (Вольф, Разумникова, 2004).

\section{ОПИСАНИЕ ЭКСПЕРИМЕНТААЬНОГО ИССАЕАОВАНИЯ}

В ходе нашего исследования 2014 г. мы использовали технику, позволяющую выявить различия лево- и правополушарных стратегий в решении задачи измерения точности восприятия заданного образца. Она определялась путем вычисления ошибки при воспроизведении образца путем нажатия рукой на клавишу измерительного прибора: испытуемые нажимали на клавишу с усилием в 1,5 кг, запоминали его, отслеживая соответствие стрелки вольтметра заданной отметке на экране. После того как реципиенты говорили, что запомнили усилие, вольтметр убирали и они воспроизводили усилие по памяти. Результат фиксировали, и, таким образом, определялась ошибка восприятия. Аля того чтобы выявить влияние психоэмоционального состояния на точность осязания, испытуемых просили выполнить интенсивные физические упражнения (прыжки в течение одной минуты), после которых измерения повторялись. Таким образом, измерялась точность восприятия в состоянии спокойного бодрствования и психоэмоционального возбуждения.

В ходе нашего экспериментального исследования была осуществлена попытка изучения «вклада» полушарий в точность восприятия. Испытуемых просили воспроизвести заданный образец сначала отдельно правой и левой рукой (соответственно пробы 1 и 2), а затем осуществить одновременное нажатие обеими руками (проба 3). Исследования проводились в два этапа: на первом этапе измерения осуществлялись в состоянии спокойного бодрствования испытуемых, на втором - в состоянии психического возбуждения после интенсивной физической нагрузки (прыжки с попеременно высоко поднимаемыми коленями в быстром темпе в течение одной минуты). Повто- 
рим, в каждом состоянии испытуемым предлагались три замера, таким образом, было произведено шесть проб.

Аля проведения экспериментального исследования был изготовлен измерительный прибор (разработчик А. М. Черепанов, ведущий конструктор Научно-исследовательского института современных телекоммуникационных технологий г. Смоленска), представляющий собой корпус с габаритными размерами 35 х 5 х 5 см. На лицевой панели расположены четыре светодиода и два рычага (для левой и правой руки), измеряющие усилия испытуемых, создаваемые давлением больших пальцев кистей рук на датчики силы (рычаги). Аля индикации измеряемой силы к корпусу прибора через специальный разъем подключается стрелочный вольтметр. Усилия измеряются от 0 до 20 ньютонов (что соответствует 2 кг).

\section{ОБСУЖАЕНИЕ РЕЗУАЬТАТОВ}

Результаты испытуемых представлены в таблице (см. с. 282).

Таблица состоит из двух частей. В первой части представлены результаты воспроизведения образца испытуемыми в состоянии спокойного бодрствования, во второй части - в состоянии психоэмоционального возбуждения после прыжков. Каждая часть состоит из четырех столбцов, в которых представлены ошибки заданного образца испытуемыми, допущенные при поочередном воспроизведении правой и левой руками (столбцы $3,4,7$ и 8) и далее при воспроизведении обеими руками одновременно (столбцы 5, 6, 9, 10 соответственно). При воспроизведении усилия обоими руками одновременно были получены результаты измерений по правой и левой руке отдельно. В строке «среднее значение» отражены средние арифметические значения по группе по всем пробам. Как видно из таблицы, наиболее высокую точность восприятия заданного образца испытуемые демонстрируют в состоянии спокойного бодрствования при его воспроизведении правой рукой: ошибка - 34,21. Ошибка левой руки превышает ошибку правой приблизительно втрое - 96,05. Аругими словами, различие ошибок правой и левой рук в состоянии спокойного бодрствования выражено значительно: правая (ведущая) рука воспроизводит образец точнее левой.

Состояние возбуждения оказывает влияние на точность восприятия: левая рука «ошибается», во-первых, меньше правой $(75,37$ и 77,15 соответственно, столбцы 7 и 8). И во-вторых, точность левой руки в состоянии возбуждения выше, чем в состоянии спокойного бодрствования $(77,15$ и 96,5 соответственно), в то время как точность правой руки выше в состоянии спокойного бодрствования и, наоборот, значительно ниже в состоянии возбуждения $(34,21$ и 75,37$)$. Эти результаты подтвердили ранее полученные данные: состояние возбуждения оказывает влияние на точность восприятия: точность воспроизведения образца правой рукой значительно снижается, а левой - повышается (Полякова, 2015).

Результаты испытуемых при воспроизведении заданного образца правой и левой руками одновременно в разных психоэмоциональных состояниях (спокойного бодрствования и возбуждения) выявили более высокую по сравнению с левой рукой точность правой руки (спокойное бодрствование: 70,84 - правая рука, 92,58 - левая рука; состояние возбуждения: 57,53 правая рука, 76,79 - левая рука). Как оказалось в ходе анализа результатов данной группы, точность воспроизведения образца испытуемыми обеими руками в состоянии возбуждения превосходит аналогичные результаты в состоянии спокойного бодрствования, причем повышается точность воспроизведения обоими руками. 
РЕЗУАЬТАТЫ ВОСПРОИЗВЕАЕНИЯ ЗАААННОГО ОБРАЗЦА ИСПЫТУЕМЫМИ АО И ПОС Е ФИЗИЧЕСКОЙ НАГРУЗКИ

REPRODUCTION OF PATTERNS BY THE SUBJECTS BEFORE AND AFTER PHYSICAL EXERCISE

\begin{tabular}{|c|c|c|c|c|c|c|c|c|c|}
\hline \multirow{4}{*}{ № } & \multirow{4}{*}{ 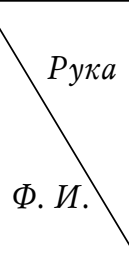 } & \multicolumn{8}{|c|}{ Ошибка воспроизведения заданного образиа } \\
\hline & & \multicolumn{4}{|c|}{ до физической нагрузки } & \multicolumn{4}{|c|}{ после физической нагрузки } \\
\hline & & \multicolumn{2}{|c|}{$\begin{array}{c}\text { поочередно } \\
\text { разными руками }\end{array}$} & \multicolumn{2}{|c|}{$\begin{array}{c}\text { обе руки } \\
\text { одновременно }\end{array}$} & \multicolumn{2}{|c|}{$\begin{array}{c}\text { поочередно } \\
\text { разньми руками }\end{array}$} & \multicolumn{2}{|c|}{$\begin{array}{c}\text { обе руки } \\
\text { одновременно }\end{array}$} \\
\hline & & правая & левая & правая & левая & правая & левая & правая & левая \\
\hline 1 & 2 & 3 & 4 & 5 & 6 & 7 & 8 & 9 & 10 \\
\hline 1 & A. E. & 0,13 & 1,24 & 0,55 & 1,50 & 0,17 & 0,82 & 0,51 & 1,20 \\
\hline 2 & A. M. & $-0,49$ & 1,02 & $-1,15$ & $-1,22$ & 1,19 & 0,86 & 1,31 & 0,40 \\
\hline 3 & А. Ю. & 0,01 & 1,54 & 1,16 & 1,97 & 1,45 & 1,16 & 0,57 & 0,67 \\
\hline 4 & Б. Р. & $-0,11$ & $-1,30$ & $-0,46$ & $-1,28$ & 0,66 & $-0,20$ & 0,33 & $-0,84$ \\
\hline 5 & Б. A. & $-0,03$ & 1,05 & 0,32 & 0,98 & 0,35 & 0,11 & 0,33 & 0,86 \\
\hline 6 & B. A. & $-0,08$ & 0,89 & $-1,31$ & $-1,16$ & 1,84 & 2,49 & 0,41 & $-0,11$ \\
\hline 7 & B. B. & $-0,53$ & $-0,44$ & 0,68 & 0,27 & 1,05 & 0,21 & $-0,32$ & 1,02 \\
\hline 8 & B. E. & 0,56 & 1,17 & 1,09 & 1,51 & 1,74 & 2,37 & 0,69 & 2,08 \\
\hline 9 & A. $\mathrm{O}$. & $-0,64$ & 0,00 & $-0,15$ & $-0,05$ & 0,82 & 1,28 & 0,60 & 1,67 \\
\hline 10 & E. T. & $-0,36$ & $-0,29$ & $-0,33$ & $-0,41$ & 0,57 & 0,41 & $-0,22$ & $-0,64$ \\
\hline 11 & 3. H. & $-1,12$ & $-1,5$ & $-1,13$ & $-1,31$ & $-0,08$ & $-0,38$ & $-1,19$ & $-0,65$ \\
\hline 12 & М. И. & $-0,37$ & 0,10 & $-0,37$ & $-0,18$ & 0,22 & $-0,04$ & 0,28 & 0,22 \\
\hline 13 & H. A. & $-0,12$ & 0,65 & 0,26 & 0,66 & 0,06 & 0,69 & $-0,86$ & 0,14 \\
\hline 14 & H. C. & 0,05 & 0,83 & $-0,79$ & $-0,74$ & $-0,70$ & $-0,39$ & $-1,08$ & $-0,93$ \\
\hline 15 & H. A. & 0,46 & 1,50 & 0,00 & 0,88 & 0,13 & 0,81 & 0,11 & 0,82 \\
\hline 16 & C. E. & $-0,21$ & $-0,54$ & $-0,39$ & $-0,36$ & 0,69 & $-0,14$ & 1,26 & 0,62 \\
\hline 17 & C. A. & 0,40 & 1,53 & 0,67 & 0,74 & 0,51 & 0,22 & 0,52 & 0,44 \\
\hline 18 & Y. A. & 0,29 & 0,94 & 0,17 & 0,94 & 0,70 & 1,07 & $-0,25$ & 0,89 \\
\hline 19 & Ф. A. & 0,54 & 1,72 & 2,48 & 1,43 & 1,73 & 0,67 & 0,89 & 0,79 \\
\hline \multicolumn{2}{|c|}{ Всего } & 650 & 1825 & 1346 & 1759 & 1466 & 1432 & 1093 & 1459 \\
\hline \multicolumn{2}{|c|}{$\begin{array}{l}\text { Среднее } \\
\text { значение }\end{array}$} & 34,21 & 96,05 & 70,84 & 92,58 & 77,15 & 75,37 & 57,53 & 76,79 \\
\hline
\end{tabular}

Итак, на воспроизведение образца обеими руками одновременно влияет интерференция межполушарной асимметрии, она проявляется по-разному в различных психоэмоциональных состояниях, однако ошибка воспроизведения образца левой рукой во всех случаях выше правой. Величина ошибки зависит от психоэмоционального состояния испытуемого в момент воспроизведения. В состоянии спокойного бодрствования точность правой руки, так же как и при поочередном воспроизведении правой 
и левой рукой, выше левой (правая: 70,84 и 57,53 соответственно; левая: 92,58 и 76,79 соответственно).

\section{ЗАКАЮЧЕНИЕ}

В ходе проведенного исследования была подтверждена гипотеза о том, что психоэмоциональное состояние испытуемого и локальные межполушарные взаимодействия влияют на точность восприятия и последующее воспроизведение заданного образца. Заметим, что точность левой руки в обоих случая при одновременном нажатии остается относительно неизменной величиной по сравнению с результатами правой руки. Причем в состоянии возбуждения при одновременном нажатии повышается точность воспроизведения правой рукой, хотя это было нехарактерно в предыдущих случаях. При одновременном нажатии в состоянии возбуждения левая рука «влияет» на снижение точности правой руки, как бы увеличивая ее ошибку, степень ее увеличения зависит от психоэмоционального состояния испытуемого.

Как выяснилось в ходе исследования, метрическая обработка эталонов восприятия не является однозначной, ее точность зависит от эмоционального состояния и локальных межполушарных взаимодействий, обеспечивающих соответствующую константность перцептивных эталонов в зависимости от того, какой рукой (правой или левой или обеими руками одновременно) осуществлялось воспроизведение заданного образца. Наиболее информативной, как выяснилось в ходе исследования, является ошибка правой руки в состоянии спокойного бодрствования.

\section{СПИСОК АИТЕРАТУРЫ}

Ахметова, А. В. (2005) Половозрастные особенности развития когнитивной сферы личности учащихся начальных классов // Вестник ТГПУ. Сер. Психология. Вып. 1 (45). С. 18-20.

Безруких, М. М., Хрянин, А. В., Теребова, Н. Н. (2013) Возрастные и половые особенности психофизиологической структуры зрительного восприятия у детей 5-7 лет // Новые исследования. Вып. 4 (37). С. 20-36.

Вольф, Н. В., Разумникова, О. М. (2004) Половой диморфизм функциональной организации мозга при обработке речевой информации // Функциональная межполушарная асимметрия : хрестоматия / под ред. Н. Н. Боголепова, В. Ф. Фокина. М. : Научный мир. 728 с.

Гончаров, О. А., Емельянова, Н. Е., Тяповкин, Ю. Н. (2011) Топологический и метрический принципы обработки пространственной информации // Психологический журнал. Т. 32. № 1. C. 87-96.

Грушенко, В. И. (2012) Стратегии управления бизнесом. От теории к практической разработке и реализации. М. : ЮНИТИ-ААНА ; Закон и право. 295 с.

Амитриева, Е. С., Андерсон, М. Н., Гельман, В. Я. (2016) Сравнительное исследование зрительного и слухового восприятия эмоций детьми младшего школьного возраста // Экспериментальная психология. Т. 9. № 1. С. 38-52. DOI:10.17759/ехррsy.2016090104

Еремина, А. А. (2015) Взаимосвязь эмоционально-аффективных и когнитивных компонентов психической деятельности больных, перенесших прямую реваскуляризацию миокарда // Обозрение психиатрии и медицинской психологии. № 3. С. 37-43.

Журавлева, Н. А. (2015) Аинамика экономического сознания предпринимателей в условиях макросоциальных изменений // Психологический журнал. Т. 36. № 1. С. 46-60.

Звягина, Н. В., Морозова, А. В., Теребова, Н. Н. (2011) Психофизиологические закономерности формирования системы зрительного восприятия у детей 6-8 лет. Архангельск : Поморский университет. 152 с.

Парцалис, Е. М. (2013) Факторы риска нарушений когнитивного развития у детей // Новые исследования. № 2. С. 4-22. 
Петухов, В. В. (2002) Общая психология. Тексты : в 3 т. / отв. ред. В. В. Петухов ; ред.-сост. Ю. Б. Аормашев, С. А. Капустин. 2-е изд., испр. и доп. М. : УМК Психология ; Генезис. Т. 2: Субъект деятельности. Кн. 1.527 с.

Полякова, И. В. (2015) Влияние эмоциональных ситуаций на функционирование перцептивной сферы и свойства личности // Вестн. Волгоградского ун-та. Сер. 11. Естественные науки. № 2 (12). C. 113-126. DOI: 10.15688/jvolsu11.2015.2.14

Полякова, И. В. (2007) Психологические особенности формирования ценностей предпринимателей: операционно-технический аспект // Опыт, проблемы и перспективы подготовки специалистов высших учебных заведениях России : материалы II Всерос. науч.-практ. конф., 29 апреля 2007 г., г. Рославль, Смоленская область. Смоленск ; Рославль : МПСИ. С. 286-295.

Фарбер, А. А., Бетелева, Т. Г. (2005) Формирование системы зрительного восприятия в онтогенезе // Физиология человека. № 5. С. 26-36.

Bryden, M. P., George, J., Inch, R. (1990) Sex differences and the role of figural complexity in determining the rate of mental rotation // Perceptual and Motor Skills. Vol. 70. P. 467-477. DOI: 10.2466/pms.1990.70.2.467

Coluccia, E., Louse, G. (2004) Gender differences in spatial orientation: A review // Journal of Environmental Psychology. Vol. 24. P. 329-340. DOI: 10.1016/j.jenvp.2004.08.006

Duemmler, T., Franz, V. H., Jovanovic, B., Schwarzer, G. (2008) Effects of the Ebbinghaus illusion on children's perception and grasping // Experimental Brain Research. Vol. 186. Issue 2. P. 249-260. DOI: $10.1007 / \mathrm{s} 00221-007-1229-0$

Ganel, T., Goodale, M. A. (2003) Visual control of action but not perception requires analytical processing of object shape // Nature. Vol. 426. P. 664-667. DOI:10.1038/nature02156

Hanisch, C. Konczak, J., Dohle, C. (2001) The effect of the Ebbinghaus illusion on grasping behavior of children // Experimental Brain Research. Vol. 137. P. 237-245. DOI: 10.1007/s002210000655

Kramer, J. H., Ellenberg, L., Leonard, J., Share, L.J. (1996) Developmental sex differences in global-local perceptual bias // Neuropsychology. Vol. 10. P. 402-407. DOI: 10.1037/0894-4105.10.3.402

Schum, N., Franz, V. H., Jovanovic, B., Schwarzer G. (2012) Object processing in visual perception and action in children and adults // Journal of Experimental Child Psychology. Vol. 112. Issue 2. P. 161-177. DOI:10.1016/j.jecp.2012.02.008

Tzuriel, D., Egozi, G. (2010) Gender Differences in Spatial Ability of Young Children: The Effects of Training and Processing Strategies // Child Development. Vol. 81. №5. P. 1417-1430. DOI: 10.1111/j.1467-8624.2010.01482.x

Аата поступления: 14.03.2016 г.

\section{PSYCHOLOGICAL PECULIARITIES OF METRICAL PROCESSING OF PERCEPTION PATTERNS}

\section{V. Poliakova \\ (SMOLENSK STATE UNIVERSITY)}

The article deals with the issue of perceptual constancy and the role it played in the adaptation of man to the social and cultural environment. Our aim was to determine the psychological factors which affect the test subjects' accuracy of pattern perception. Our hypothesis is that both the psycho-emotional state of the subject and local interaction between the hemispheres of the brain influence the accuracy of perception and subsequent reproduction of patterns.

To test the matter experimentally, we used the help of 19 undergraduate students in their $4^{\text {th }}$ year at the faculty of psychology and pedagogy, Smolensk state University. In the course of experiment conducted in March 2014, we measured the accuracy of reproduction of a given pattern by pressing the keys of the measuring device alternately and then simultaneously with the right and left hands. The device was specially designed for the experiment and allowed to set the margin of reproduction error automatically directly in the process. Series of measurements were carried out while subjects experienced two kinds of emotional states - quiet wakefulness or excitement after intense physical exercise. 
Comparative mapping of the obtained results confirmed our hypothesis about the impact the psycho-emotional state and interhemispheric links have on the accuracy of perception and subsequent reproduction of a pattern. It also shed some light on how hemispheric asymmetry contributes to reproducing the perceived pattern. The experiment also discovered that the most informative indicator of a subject's 'perceptual maturity' is the magnitude of error in perception and subsequent reproduction of a pattern while in the state of quiet wakefulness.

Keywords: genesis of perception; metrical processing; cognitive processes; perceptual constancy; accuracy of perception; hemispheric asymmetry; mental strain; emotional excitement; state of quiet wakefulness; gender differences

\section{REFERENCES}

Akhmetova, L. V. (2005) Polovozrastnye osobennosti razvitiia kognitivnoi sfery lichnosti uchashchikhsia nachal'nykh klassov [Gender- and age-specific development of the cognitive sphere in primary school students]. Vestnik TGPU. Series Psychology, iss. 1 (45), pp.18-20. (In Russ.).

Bezrukikh, M. M., Khrianin, A. V. and Terebova, N. N. (2013) Vozrastnye i polovye osobennosti psikhofiziologicheskoi struktury zritel'nogo vospriiatiia u detei 5-7 let [Gender- and age-specific factors in the psychophysiological structure of visual perception in children aged 5-7]. Novye issledovaniia, iss. 4 (37), pp.20-36. (In Russ.).

Vol'f, N. V. and Razumnikova, O. M. (2004) Polovoi dimorfizm funktsional'noi organizatsii mozga pri obrabotke rechevoi informatsii [Sexual dimorphism of functional structure of the brain in speech procession]. In: Funktsional' naia mezhpolusharnaia asimmetriia : kbrestomatiia [Functional hemispheric asymmetry: A reader]/ ed. by N. N. Bogolepov and V. F. Fokin. Moscow, Nauchnyi mir Publ. 728 p. (In Russ.).

Goncharov, O. A., Emel'ianova, N. E. and Tiapovkin, Iu. N. (2011) Topologicheskii i metricheskii printsipy obrabotki prostranstvennoi informatsii [Topological and metrical principles in processing spatial information] Psikbologicheskii zhurnal, vol. 32, no. 1, pp. 87-96. (In Russ.).

Grushenko, V. I. (2012) Strategii upravleniia biznesom. Ot teorii $k$ prakticheskoi razrabotke $i$ realizatsii [Strategies of business administration: From theory to practice and implementation]. Moscow, IuNITI-DANA ; Zakon i pravo Publ. 295 p. (In Russ.).

Dmitrieva, E. S., Anderson, M. N. and Gel'man, V. Ia. (2016) Sravnitel'noe issledovanie zritel'nogo i slukhovogo vospriiatiia emotsii det'mi mladshego shkol'nogo vozrasta [A comparative study of visual and audial perception of emotion by primary school students]. Eksperimental' naia psikhologiia, vol. 9, no. 1, pp.38-52. (In Russ.). DOI: 10.17759/exppsy.2016090104

Eremina, D. A. (2015) Vzaimosviaz' emotsional'no-affektivnykh i kognitivnykh komponentov psikhicheskoi deiatel'nosti bol'nykh, perenesshikh priamuiu revaskuliarizatsiiu miokarda [A correlation between affective and cognitive components in patients with acute myocardial infarction]. Obozrenie psikbiatrii i meditsinskoi psikbologii, no. 3, pp. 37-43. (In Russ.).

Zhuravleva, N. A. (2015) Dinamika ekonomicheskogo soznaniia predprinimatelei v usloviiakh makrosotsial'nykh izmenenii [The dynamics of change in the entrepreneurs' economic consciousness under macrosocial transformations]. Psikbologicheskii zhurnal, vol. 36, no. 1, pp.46-60. (In Russ.).

Zviagina, N. V., Morozova, L. V. and Terebova, N. N. (2011) Psikbofiziologicheskie zakonomernost i formirovaniia sistemy zritel' nogo vospriiatiia u detei 6-8 let [Psychophysiological principles of visual perception in children aged 6-8]. Arkhangel'sk, Pomorskii universitet Publ. 152 p. (In Russ.).

Partsalis, E. M. (2013) Faktory riska narushenii kognitivnogo razvitiia u detei [Risk factors for cognitive impairments in children]. Novye issledovaniia, no. 2, pp.4-22. (In Russ.)

Petukhov, V. V. (2002) Obshchaia psikbologiia. Teksty [General Psychology: A textbook]: in 3 vols. / ed. by V. V. Petukhov. 2nd edn., augm. and exp. Moscow, UMK Psikhologiia ; Genezis Publ. Vol. 2: Sub»ekt deiatel'nosti [The subject of activity]. Bk. 1. 527 p. (In Russ.).

Poliakova, I. V. (2015) Vliianie emotsional'nykh situatsii na funktsionirovanie pertseptivnoi sfery i svoistva lichnosti [The impact of emotional states on the function of the perceptive sphere and traits of personality]. Vestnik Volgogradskogo universiteta. Series 11. Natural sciences, no. 2 (12), pp. 113-126. (In Russ.). DOI: 10.15688/jvolsu11.2015.2.14 
Poliakova, I. V. (2007) Psikhologicheskie osobennosti formirovaniia tsennostei predprinimatelei: operatsionno-tekhnicheskii aspekt [Psychological aspects of value-building in entrepreneurs: the functional and technical aspect]. In: Opyt, problemy $i$ perspektivy podgotovki spetsialistov vysshikb uchebnykh zavedeniiakb Rossii : materialy II Vseros. nauch.-prakt. konf., 29 aprelia 2007 g., g. Roslavl', Smolenskaia oblast' [The experience, issues and prospects of training professionals at institutions of higher education in Russia. Proceedings of 2nd All-Russia research conference, April 29, 2007, Roslavl', Smolensk Oblast]. Smolensk, Roslavl', MPSI Publ. Pp.286-295. (In Russ.)

Farber, D. A. and Beteleva, T. G. (2005) Formirovanie sistemy zritel'nogo vospriiatiia v ontogeneze [The system of visual perception and its rise in ontogenesis]. Fiziologiia cheloveka, no. 5, pp.26-36. (In Russ.).

Bryden, M. P., George, J. and Inch, R. (1990) Sex differences and the role of figural complexity in determining the rate of mental rotation. Perceptual and Motor Skills, vol. 70, pp. 467-477. DOI: 10.2466/pms.1990.70.2.467

Coluccia, E. and Louse, G. (2004) Gender differences in spatial orientation: A review. Journal of Environmental Psychology, vol. 24, pp. 329-340. DOI: 10.1016/j.jenvp.2004.08.006

Duemmler, T., Franz, V. H., Jovanovic, B. and Schwarzer, G. (2008) Effects of the Ebbinghaus illusion on children's perception and grasping. Experimental Brain Research, vol. 186, issue 2, pp. 249-260. DOI: $10.1007 /$ s00221-007-1229-0

Ganel, T. and Goodale, M. A. (2003) Visual control of action but not perception requires analytical processing of object shape. Nature, vol. 426, pp. 664-667. DOI:10.1038/nature02156

Hanisch, C. Konczak, J. and Dohle, C. (2001) The effect of the Ebbinghaus illusion on grasping behavior of children. Experimental Brain Research, vol. 137, pp. 237-245. DOI 10.1007/ s002210000655

Kramer, J. H., Ellenberg, L., Leonard, J. and Share, L. J. (1996) Developmental sex differences in global-local perceptual bias. Neuropsychology, vol. 10, pp. 402-407. DOI: 10.1037/08944105.10.3.402

Schum, N., Franz, V. H., Jovanovic, V. and Schwarzer G. (2012) Object processing in visual perception and action in children and adults. Journal of Experimental Child Psychology, vol. 112, issue 2, pp. 161-177. DOI:10.1016/j.jecp.2012.02.008

Tzuriel, D. and Egozi, G. (2010) Gender Differences in Spatial Ability of Young Children: The Effects of Training and Processing Strategies. Child Development, vol. 81, no. 5, pp. 1417-1430. DOI: 10.1111/j.1467-8624.2010.01482.x

Submission date: 14.03 .2016

Полякова Ирина Вадимовна - кандидат психологических наук, доцент кафедры общей психологии Смоленского государственного университета. Адрес: 214000, Смоленск, ул. Пржевальского, А. 4, кафедра общей психологии. Тел.: +7 (910) 726-30-10. Эл. адрес: alisapolyak2810@mail.ru

Poliakova Irina Vadimovna, Candidate of Psychology, Associate Professor, Department of general psychology, Smolensk State University. Postal address: 4 Przevalsky St., Smolensk, Russian Federation 214000. Tel.: +7 (910) 726-30-10. E-mail: alisapolyak2810@mail.ru 